\title{
Biosynthesis, characterization and antimicrobial activity of gold nanoparticles from leaf extracts of Annona muricata
}

\author{
Aderonke Folorunso $^{1}$ - Sunday Akintelu ${ }^{2}$ (1) $\cdot$ Abel Kolawole Oyebamiji $^{2,4} \cdot$ Samuel Ajayi $^{3} \cdot$ Babawale Abiola $^{2}$. \\ Ibrahim Abdusalam ${ }^{5}$. Adetoun Morakinyo ${ }^{6}$
}

Received: 4 March 2019 / Accepted: 22 April 2019 / Published online: 29 April 2019

(c) The Author(s) 2019

\begin{abstract}
The need to divulge the rapid synthesis, non-hazardous, cost effectiveness and eco-friendly methods for the synthesis of nanoparticles utilizing plants is of great importance. This is as a result of high toxicity associated with the chemical method of synthesizing nanoparticles. The aim of this study was to investigate the potency of the synthesized gold nanoparticle against selected human pathogens. Gold nanoparticles were synthesized by reacting $1 \mathrm{mM}$ gold chloride solution with leaf extract of Annona muricata. The synthesized gold nanoparticles were characterized with UV-visible spectrophotometer, transmission electron microscope (TEM) and Fourier transformed infrared spectroscopy (FTIR). The antibacterial and antifungal activities of the synthesized gold nanoparticles were also investigated. The morphology, size, and structural properties of synthesized gold nanoparticles were determined with TEM analysis which showed spherical mono-dispersed structure with an average particle size of $25.5 \mathrm{~nm}$. FTIR analysis reveal band at $3271.14,2111.91$ and $1637.82 \mathrm{~cm}^{-1}$ corresponding to $-\mathrm{N}-\mathrm{H},-\mathrm{C}=\mathrm{C}$, and $-\mathrm{C}-\mathrm{N}$ functional groups that are responsible for the capping and stabilization of synthesized gold nanoparticles. The effectiveness of the gold nanoparticle against the test pathogens increases as the concentration of gold nanoparticle increases. The percentage of zones of inhibition of synthesized gold nanoparticle against test fungi and bacteria ranges from 30 to $66 \%$ and 40 to $54 \%$, respectively. The potency of the synthesized gold nanoparticle against the selected fungi and bacteria increases with increase in concentration of gold nanoparticle. Therefore, the antibacterial and antifungal investigation revealed that the synthesized gold nanoparticles exhibited good antimicrobial activity.
\end{abstract}

Keywords Characterization $\cdot$ Antimicrobial $\cdot$ Gold nanoparticles $\cdot$ Annona muricata

\section{Introduction}

In modern materials sciences nanotechnology is one of the imperative approach used to detect nano-substance which has found numerous applications in various fields such as pharmaceutical and biomedical sciences [1]. Previously, nanoparticles were synthesized by chemical method where chemicals act as the reducing agents. But the toxicity and probable risk on human health and environment are major limitations to this approach, the biological methods which use plants is more preferable because of its nontoxicity, tranquil scaling-up, and reproducibility in making [2, 3]. The greener method of phytomediated synthesis of gold nanoparticles using dalspinin at room temperature has been reported not to toxic [4]. The development of an eco-friendly procedure for the synthesis of nanoparticle via the biological method using plants arises as a result of the hazardous effect of the chemical and physical methods of synthesizing

6 Department of Biochemistry, Adeleke University, P.M.B. 250, Ede, Nigeria 
nanoparticles. The bioactive compounds present in plants act as reducing agents which helps in the reduction of metal ions to metal nanoparticles with distinct size, shapes and significant antimicrobial efficiency [5]. The antimicrobial potency of nanoparticles and its small size motivate researchers in evaluating different methods for the synthesis of highly mono-dispersed nanoparticles with verified antimicrobial activities [6]. The antimicrobial properties of the nanoparticles synthesized from Annona muricata extract showed a great inhibition against Gram-positive and Gram-negative bacteria, the growing resistant strains developed by microbes against metal ions and antibiotics coupled with the good antibacterial properties of gold nanoparticles are the major interest of researchers in green synthesize of gold nanoparticles [7, 8]. Among other metal nanoparticles gold nanoparticle exhibits effective antimicrobial property due to its tremendously large surface area, which provides better contact with microorganisms [9]. The high chemical stability, optical properties, oxidation resistance and biocompatibility properties of gold nanoparticles and their applications in different field of study such as biology, optics and medicine make synthesis of gold nanoparticles an interesting object of study [10]. The advantage of synthesizing gold nanoparticles from plant extract is not limited to reduction of environmental toxicity, the production of nanoparticles in large quantities, simplicity of reducing metal salts, rapid, cost effective, and safety for clinical research to nanoparticles are other advantages associated with this method of synthesis, the green synthesized gold nanoparticle can be used in development of catalysts, sensors, nano medicine and biomarker applications [11]. Gold nanoparticles exhibit properties that are different from that of bulk gold and can be manufactured into various shapes such as nanorods, nanostars, nanobelts, nanospheres, nanocages and nanoprisms [12]. The size, high surface area, and shapes of gold nanoparticles have influenced its chemical properties and have increased its applications especially in the field of medicine [13]. From traditional age to modern age entire part of $A$. muricata plant have been reported to provide vast medicinal benefits to human by curing ailments such as bacteria, fungi, cancer, tumor, arthritic, diabetics, inflammation, sedative, diarrheal and diuretic infections
[14]. This study was aimed at the investigation of stable and efficient process for the synthesis of gold nanoparticle using A. muricata leaf via the characterization and pharmacological activities evaluation.

\section{Materials and methods}

\section{Preparation of leaf extract}

The leaves of A. muricata were collected from the premises of botany department of Obafemi Awolowo University, IleIfe, Nigeria and were authenticated. The leaves were properly washed, air dried and pulverized with blender grinder. $20 \mathrm{~g}$ of the pulverized leaves sample of A. muricata was transferred into a $200 \mathrm{ml}$ Erlenmeyer flask, $150 \mathrm{ml}$ of de-ionized water was added and boiled for $20 \mathrm{~min}$. The boiled plant extract was cooled at room temperature and filtered with (Whatman filter paper No. 1). This extract was further used for the synthesis of gold nanoparticles. The fresh, air-dried and pulverized leaves of A. muricata are showed in Fig. 1.

\section{Biosynthesis of gold nanoparticles}

The method of [15] was adopted in the synthesis of the gold nanoparticles. $1 \mathrm{ml}$ of the obtained leaf extract was added to $1 \mathrm{mM}$ solution of gold chloride and stirred properly at room temperature until the yellow color of the extract changed to purple color that confirmed the synthesis of gold nanoparticles. The mixture was incubated for $22 \mathrm{~h}$ for thorough bioreduction of gold chloride to gold nanoparticles from leaf extract. The reduction of gold chloride to gold nanoparticles was monitored with UV-Vis spectrometer by recording the $\mathrm{UV}-\mathrm{Vis}$ absorption spectrum as a function of time.

\section{UV-visible spectroscopy}

UV-Vis spectrometer (UV-245 Shimadzu) was used at various time intervals to ascertain the optimum concentration of plant extracts. The purple color confirmed the formation of the gold nanoparticle. The formation of the
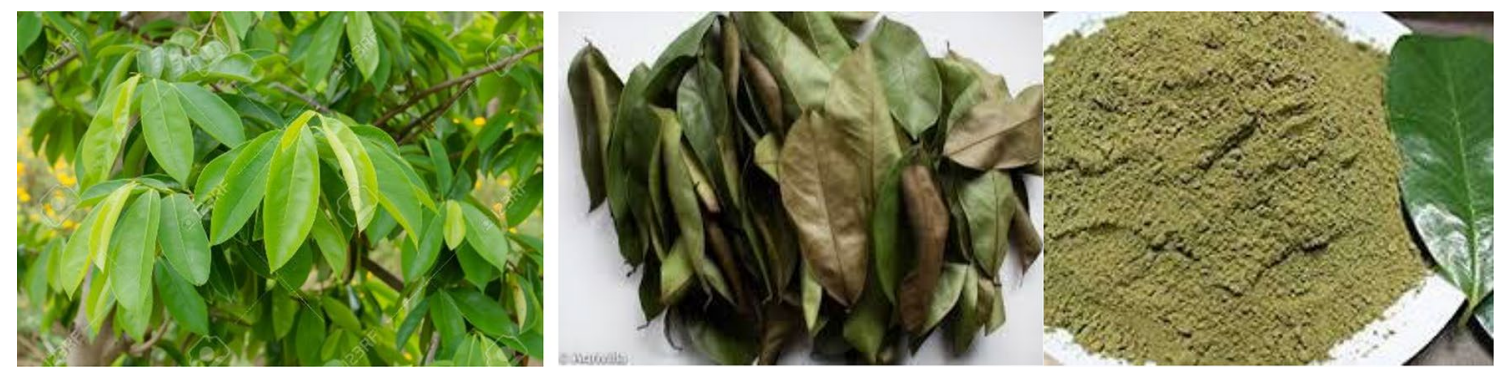

Fig. 1 Fresh, air-dried and pulverized leaves sample of Annona muricata 
gold nanoparticle was confirmed by scanning the absorption maxima of freshly prepared sample of gold nanoparticle using $1 \mathrm{~cm}$ path length quartz cuvettes at temperature range of $24-28{ }^{\circ} \mathrm{C}$ at wavelength $450-850 \mathrm{~nm}$.

\section{FTIR spectroscopy}

The FTIR analysis was determined with FTIR spectrometer, Nicolet iS50 (Thermo Fisher Scientific, Waltham, MA, USA). The freeze-dried gold nanoparticle extract was mixed with KBR (FTIR grade) and scanned on FTIR over the range of $4000-380 \mathrm{~cm}^{-1}$ at a resolution of $4 \mathrm{~cm}^{-1}$. FTIR analysis was used for the identification of functional group present and to study the interactions of the functional groups as a source of reducing agents on the surface of synthesized nanoparticles.

\section{Transmission electron microscopy}

The particle size and surface morphology of synthesized gold nanoparticle were measured with transmission electron microscopy (TEM) JEOL model 1200EX, at an accelerating voltage of 80 kilo voltage. The synthesized gold nanoparticle samples were prepared by dropping few drops of the gold nanoparticle solution on Lacey carbon grids, 300 mesh and allowed the grid to dry before measurement.

\section{Antibacterial investigation of gold nanoparticles}

The investigation of the antibacterial potency of the synthesized gold nanoparticle against some clinical isolates bacteria was conducted following the standard well diffusion procedures [16]. Freshly cultures prepared overnight were spread on sterilized nutrient agar plates. Sterile cork borer was used to bore $8 \mathrm{~mm}$ diameter wells in the agar plates. The wells were loaded with $50 \mu \mathrm{l}$ of $2 \mathrm{mg} / \mathrm{l}$ and $4 \mathrm{mg} / \mathrm{l}$ concentration of gold nanoparticle solution and $2 \mathrm{mg} / \mathrm{l}$ of an antibiotic (Streptomycin) was used as positive control. The incubation of the plates at $37^{\circ} \mathrm{C}$ for $28 \mathrm{~h}$ was done. The zones of inhibition around the well impregnated with gold nanoparticle were measured and the percentage zones of inhibition were calculated to determine the antibacterial activity of the synthesized gold nanoparticle. The antibacterial investigation was on triplicate analysis. The formula below was used for the calculation of the percentage growth inhibition.

$$
\begin{aligned}
\mathrm{PGI} & =(\mathrm{BDC}-\mathrm{BDT}) / \mathrm{BDC} \times 100, \\
\mathrm{PGI} & =\text { Percent growth inhibition, } \\
\mathrm{BDC} & =\text { Bacteria colony diameter in control, } \\
\mathrm{BDT} & =\text { Bacteria colony diameter in treatment. }
\end{aligned}
$$

\section{Antifungal investigation of gold nanoparticles}

The antifungal effectiveness of the synthesized gold nanoparticle from A. muricata was investigated following the procedures described by [17]. Sterilized SDA was transferred into sterile Petri dish. After media setting, sterile gel puncture was used to puncture $8 \mathrm{~mm}$ diameter wells in the agar plates used. Forty microliters of $2 \mathrm{mg} / \mathrm{l}$ and $4 \mathrm{mg} / \mathrm{l} \mathrm{con-}$ centrations of the gold nanoparticle were introduced into the wells. Each well containing the fungal discs was inoculated in inverted position. The plates were then incubated at $28{ }^{\circ} \mathrm{C}$ for 70-94 h. Amphotercin B was used as control. The diameter of the fungal colony was measured after incubation at $28^{\circ} \mathrm{C}$ and the percentage growth inhibition was determined relatively to the fungal diameter in control. The antifungal investigation was carried out on triplicate analysis. The formula below was used for the calculation of the percentage growth inhibition:

$$
\begin{aligned}
\mathrm{PGI} & =(\mathrm{FDC}-\mathrm{FDT}) / \mathrm{FDC} \times 100, \\
\mathrm{PGI} & =\text { Percent growth inhibition }, \\
\mathrm{FDC} & =\text { Fungal colony diameter in control, } \\
\mathrm{FDT} & =\text { fungal colony diameter in treatment }
\end{aligned}
$$

\section{Results and discussion}

\section{UV analysis of gold nanoparticles}

The purple color that appeared after mixing the leaf extract of A. muricata with gold chloride solution confirmed the formation of gold nanoparticles. The resulting colloidal solutions and A. muricata extract were scanned with UV-Vis spectroscopy and the spectrum showed in Fig. 2 was obtained. The occurrence of the peak at wavelength 530 and $538 \mathrm{~nm}$ corresponds to gold absorption peaks. The variation in the absorbance-wavelength of A. muricata extract and the colloidal solutions with gold chloride confirmed the synthesis of gold nanoparticles from the leaf of A. muricata.

\section{FTIR analysis of gold nanoparticles}

FTIR analysis was carried out to determine the possible biomolecules in leaf extract of A. muricata that was responsible for capping that lead to the efficient stabilization of the gold nanoparticles. The bands observed at $3284.47,2114.93$, $1635.99 \mathrm{~cm}^{-1}$ on the FTIR spectrum of A. muricata extract as shown in (Fig. 3) and bands at 3271.14, 2111.91 and $1637.82 \mathrm{~cm}^{-1}$ on the FTIR spectrum of the synthesized gold nanoparticles from A. muricata (Fig. 4). The sharp bands at wavelength $3271.14 \mathrm{~cm}^{-1}$ corresponding to $-\mathrm{N}-\mathrm{H},-\mathrm{C}-\mathrm{N}$ and $-\mathrm{C}=\mathrm{C}-$ functional groups. These functional groups are also present in the studies $[18,19]$. The variation in 
Fig. 2 UV spectrum before and after reduction of gold nanoparticles
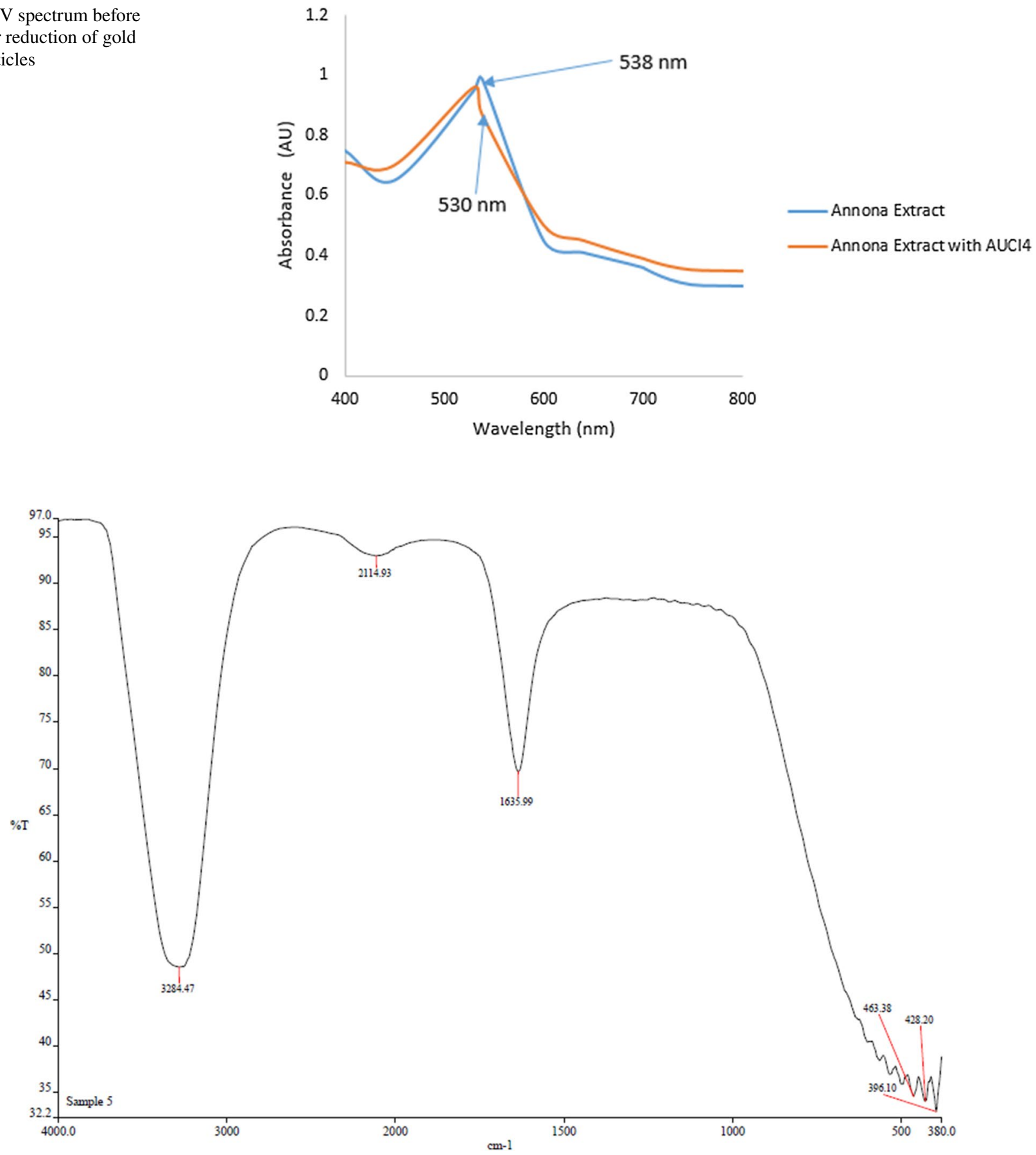

Fig. 3 FTIR spectrum of Annona muricata extract

the absorption bands observed on both spectra of the FTIR might be responsible for the reduction of gold ions, formation and stabilization of the synthesized nanoparticles from A. muricata leaves. The vibrational bands corresponding to bonds such as $-\mathrm{N}-\mathrm{H},-\mathrm{C}=\mathrm{C}-$, and $-\mathrm{C}-\mathrm{N}$ had being reported to be peculiar with flavonoids, terpenoids and protein compound [20]. This could signify that the extract has flavonoids, terpenoids and protein base compounds.

\section{TEM analysis of gold nanoparticles}

Transmission electron microscope was used to determine the size, shape and distribution of synthesized gold nanoparticles. TEM micrograph of the synthesized gold nanoparticles from A. muricata leaves shows the presence of spherical mono-dispersed nanoparticles with particle size ranging from 27 to $32 \mathrm{~nm}$ with average particle size of 
Fig. 4 FTIR spectrum of the synthesized gold nanoparticles from Annona muricata

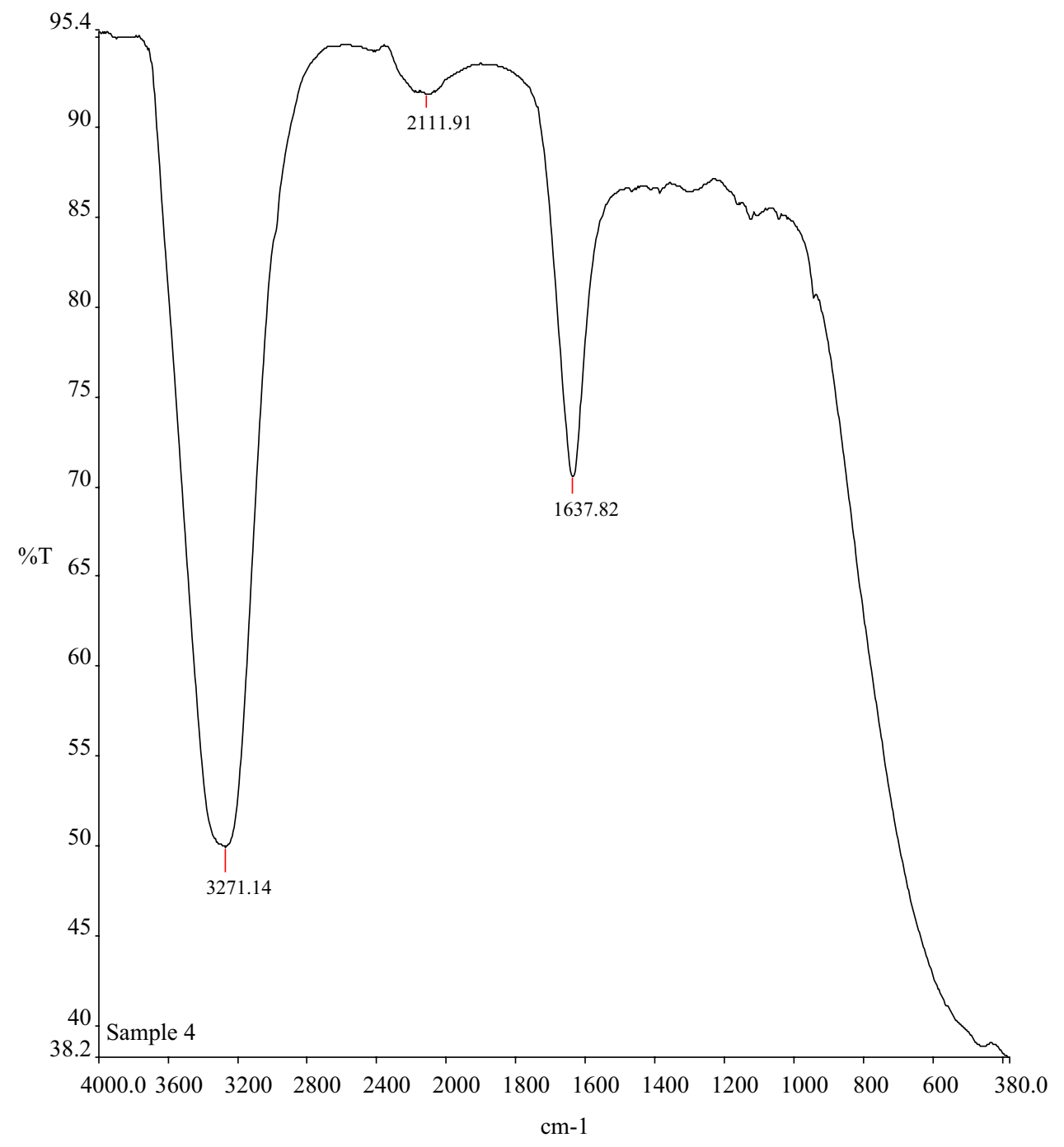

$25.5 \mathrm{~nm}$ as shown in Fig. 5. This finding is in line with the result obtained by [20] on the TEM characterization of gold nanoparticle synthesized from Periploca aphylla plant. The particle size distribution in this study is lower than that obtained by [21] but found higher than that obtained from [22] findings.

\section{Antibacterial investigation of gold nanoparticles}

The antibacterial activities of synthesized gold nanoparticles from A. muricata leaf extract against selected bacterial showed in Table 1. It was obvious from the obtained data that the synthesized gold nanoparticles were toxic against all selected bacteria at different concentrations. Clostridium sporogenes was the most susceptible bacterium to AuNps at both concentrations of $2 \mathrm{mg} / \mathrm{l}$ and $4 \mathrm{mg} / \mathrm{l}$ with maximum percentages of zones of inhibition of $50 \%$ and $54 \%$, respectively, whereas Staphyloccus aureus at both concentrations and Entrococcus faecalis at $2 \mathrm{mg} / \mathrm{l}$ concentration of synthesized gold nanoparticles were the least susceptible bacteria with $40 \%$ percentages of zones of inhibition as shown in Fig. 6. The efficacy of the gold nanoparticle against the test bacteria increases as the concentration of gold nanoparticle increases. The increasing order of potency of the synthesized gold nanoparticle against the selected pathogenic human bacteria at both concentration of gold nanoparticle was Staphyloccus aureus $>$ Entrococcus faecalis $>$ Klebsiella pneumonia $>$ Clostridium sporogenes. Previous studies revealed that plant-mediated metal nanoparticles play a crucial role in drug delivery and can be used against many microbes because of the efficiency antimicrobial properties they possess [21-23]. This suggested that the synthesized gold nanoparticle has good efficacy against bacteria and could be used in treating bacteria-infected diseases. 


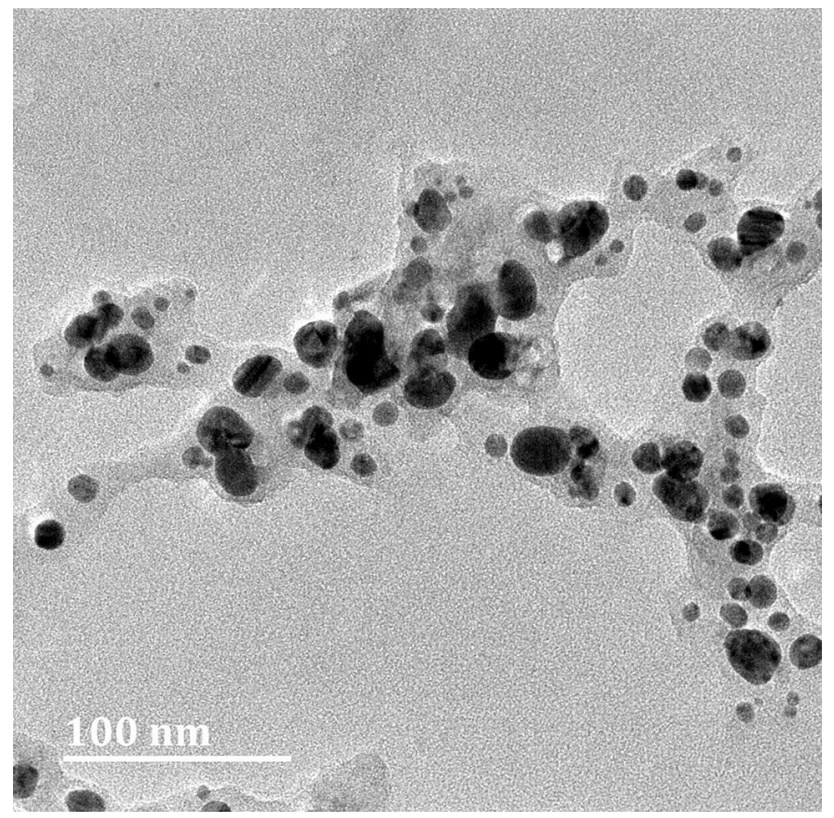

Fig. 5 TEM micrograph of the synthesized gold nanoparticles from Annona muricata

Table 1 Pathogenic bacteria and fungal used

\begin{tabular}{ll}
\hline Bacteria & Fungi \\
\hline Staphyloccus aureus & Aspergillus flaws \\
Clostridium sporogenes & Candida albican \\
Entrococcus faecalis & Fusarium oxysperium \\
Klebsiella pneumonia & Penicillium camemeri \\
\hline
\end{tabular}

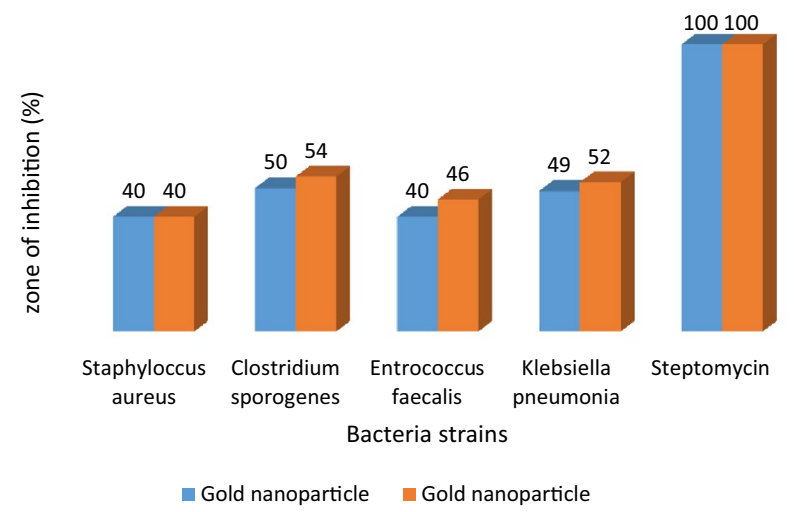

Fig. 6 Antibacterial activity of synthesized gold nanoparticle against selected bacteria strains

\section{Antifungal investigation of gold nanoparticles}

Figure 7 shows the antifungal potency of synthesized gold nanoparticle against selected fungal species Aspergillus flaws, Candida albican, Fusarium oxysperium and

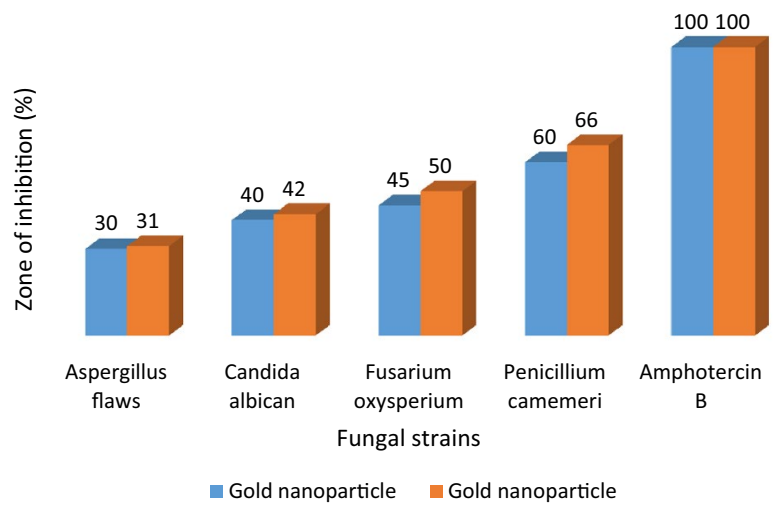

Fig. 7 Antifungal activity of synthesized gold nanoparticle against selected fungal strains

Penicillium camemeri as shown in Table 1. Highest percentage of zone of inhibition was recorded against Penicillium camemeri (66\%) at $4 \mathrm{mg} / \mathrm{l}$ gold nanoparticle while the lowest percentage of zone of inhibition was recorded against Aspergillus flaws (30\%) at concentration of $2 \mathrm{mg} / \mathrm{l}$ gold nanoparticle. The efficacy of the gold nanoparticle against the test fungal increases as the concentration of gold nanoparticle increases. The increasing order of potency of the synthesized gold nanoparticle against the selected pathogenic human fungi was Aspergillus flaws $>$ Candida albican $>$ Fusarium oxysperium $>$ Penicillium camemeri. The antifungal investigation of the synthesized gold nanoparticle from A. muricata leaves in this study was in line with previous study on antifungal activities of gold nanoparticle from different studied plants against different pathogenic human fungi where notable activity were observed [24, 25].

\section{Conclusion}

The simplicity in synthesizing gold nanoparticle from $A$. muricata leaf extract offersa valuable contribution to green synthesis and nanotechnology because of its rapid synthesis, economic effectiveness, reproducible method and large amount of gold nanoparticles was attained without any toxic reagents been released to the environment. The synthesized gold nanoparticles from A. muricata leaf extract show broad inhibition against test bacterial and fungal there by making the synthesized gold nanoparticles a good antimicrobial agent. The information obtained from this study can be adopted by drug agencies in production of antibiotics drugs which will help in combating microbes that have developed resistance against existing antibiotic drugs.

Open Access This article is distributed under the terms of the Creative Commons Attribution 4.0 International License (http://creat ivecommons.org/licenses/by/4.0/), which permits unrestricted use, 
distribution, and reproduction in any medium, provided you give appropriate credit to the original author(s) and the source, provide a link to the Creative Commons license, and indicate if changes were made.

\section{References}

1. Latha, D., Sampurnam, S., Arulvasu, C., Prabu, P., Govindaraju, K., Narayanan, V.: 2018 Biosynthesis and characterization of gold nanoparticle from Justicia adhatoda and its catalytic activity. Mater. Today Proc. 5, 8968-8972 (2018)

2. Weingart, J., Vabbilisetty, P., Sun, X.L.: Membrane mimetic surface functionalization of nanoparticles: methods and applications. Adv. Colloid Interface Sci. 197, 68-84 (2014)

3. Amit, K.M., Chisti, Y., Banerjee, U.C.: Synthesis of metallic nanoparticles using plant extracts. Biotechnol. Adv. 31, 346 (2013)

4. Umamaheswari, C., Lakshmanan, A., Nagarajan, N.S.: Green synthesis, characterization and catalytic degradation studies of gold nanoparticles against congo red and methyl orange. J. Photochem. Photobiol. B Bio 1, 4 (2018). https://doi.org/10.1016/j.jphotobiol 2017.10.017

5. Ahmed, S., Ahmad, M., Swami, B.L., Ikram, S.: A review on plants extract mediated synthesis of silver nanoparticles for antimicrobial applications: a green expertise. J. Adv. Res. 7(1), 17 (2016)

6. Linlin, C.H., Longquan, S.: The antimicrobial activity of nanoparticles: present situation and prospects for the future. Int. J. Nanomed. 12, 1227-1249 (2017)

7. del Marı, C.S., Claudio, A.R., Nereyda, N., Roberto, S., Gabriel, A.M., DeAlba-Montero, I., Facundo, R.: Cytotoxic and bactericidal effect of silver nanoparticles obtained by green synthesis method using Annona muricata aqueous extract and functionalized with 5-fluorouracil. Bioinorg. Chem. Appl. (2018). https:// doi.org/10.1155/2018/6506381

8. Sahayaraj, K., Rajesh, S.: Bionanoparticles: synthesis and antimicrobial applications. In: Mendez-Vilas, A. (ed.) Sci Against Microbial Pathogens: Research Development and Evaluation, Proceedings of the International Conference on Antimicrobial Research, pp. 228-244. World Scientific, Spain (2011)

9. Sorbiun, M., Shayegan, M.E., Ramazani, A., Mashhadi, M.A.: Biosynthesis of metallic nanoparticles using plant extracts and evaluation of their antibacterial properties. Nanochem. Res. 3(1), $1-16$ (2018)

10. Daniel, M.C., Astruc, D.: Gold nanoparticles: assembly, supramolecular chemistry, quantum-size-related properties, and applications toward biology, catalysis, and nanotechnology. Chem. Rev. 104, 293-346 (2004)

11. Vijayakumar, S.: Eco-friendly synthesis of gold nanoparticles using fruit extracts and in vitro anticancer studies. J. Saudi Chem. Soc. (2019). https://doi.org/10.1016/j.jscs.2018.12.002

12. Thakor, A.S., Jokerst, J., Zavaleta, C., Massoud, T.F., Gambhir, S.S.: Gold nanoparticles: a revival in precious metal administration to patients. Nano Lett. 11, 4029-4036 (2011)

13. Huang, X., El-Sayed, M.A.: Gold nanoparticles: optical properties and implementations in cancer diagnosis and photothermal therapy. J. Adv. Res. 1, 13-28 (2010)
14. Elavarasan, K., Govindhappa, M., Soundararajan, Stephen, D.S.: Medicinal properties and uses of sour sop (Annona muricata L.). Rashtriya Krishi 2(9), 73-75 (2014)

15. Banerjee, P., Satapathy, M., Mukhopahayay, A., Das, P.: Leaf extract mediated green synthesis of silver nanoparticles from widely available Indian plants: synthesis, characterization, antimicrobial property and toxicity analysis. Bioresour. Bioprocess. 1, 3 (2014)

16. Mubarakali, D., Thajuddina, N., Jeganathanb, K., Gunasekaranc, M.: Plant extract mediated synthesis of silver and gold nanoparticles and its antibacterial activity against clinically isolated pathogens. Colloids Surf. B Biointerfaces 85, 360 (2011)

17. Ramdas, K., Suresh, G., Janardhana, N., Masilamani, S.: Antifungal activity of 1,3-disubstituted symmetrical and unsymmetrical thioureas. J. Pest. Sci. 52, 145 (1998)

18. Hatem, F., Li, H., Hosni, D., Jiqian, W., Ghulam, A., Hassan, G., Mo, J.: Controlling Aedes albopictus and Culex pipiens pallens using silver nanoparticles synthesized from aqueous extract of Cassia fistula fruit pulp and its mode of action. Artif Cells Nanomed. Biotechnol. 46(3), 558-567 (2018)

19. Ga'al, H., Fouad, H., Tian, J., Yin, H., Abbas, G., Mo, J.: Synthesis, characterization and efficacy of silver nanoparticles against Aedes albopictus larvae and pupae. Pest. Biochem. Physiol. 144, 49-56 (2018)

20. Massoud, K., Nafiseh, Jafar, : Biosynthesis of gold nanoparticles using aqueous extract of stem of Periploca aphylla. Plant Nanostruct. 8(2), 152-158 (2018)

21. Diane, C.T., Sidney, C.M, Jet, G.G.: Biosynthesized Gold Nanoparticles (AuNPs) for the Quantitation of Mercury (II) Ions by Digital Imaging Colorimetry. http://www.aq.edu.ph/main/downl oads/pdfs/2016-2017-8.pdf. Accessed 05 Apr 2019

22. Avan, E.D., Quadry, R.O., Ikenna-Ossai, C.N., Okolie, N.P.: Effects of Annona muricata biofunctionalized gold nanoparticles on erythrocyte osmotic fragility and hematological profile in rat model. Covenant J. Phys. Life Sci. 2(1), 33-45 (2018)

23. Fouad, H., Li, H., Ding, Y., Baoting, Yu., Ahmed, E., Ghulam, A., Mo, J.: Synthesis and characterization of silver nanoparticles using Bacillus amyloliquefaciens and Bacillus subtilis to control filarial vector Culex pipiens pallens and its antimicrobial activity. Artif. Cells Nanomed. Biotechnol. 45(7), 1369-1378 (2017)

24. Thanighaiarassu, R.R., Sivamai, P., Devika, R., Nambikkairaj, B.: Green synthesis of gold nanoparticles characterization by using plant essential oil menthapiperita and their antifungal activity against human pathogenic fungi. J. Nanomed. Nanotechnol. 5, 229 (2014)

25. Khan, S., Bakht, J., Syed, F.: Green synthesis of gold nanoparticles using Acer pentapomicum leaves extract its characterization, antibacterial, antifungal and antioxidant bioassay. Dig. J. Nanomater. Biostruct. 2(13), 579-589 (2018)

Publisher's Note Springer Nature remains neutral with regard to jurisdictional claims in published maps and institutional affiliations. 